\title{
A PRÁTICA DE YOGA E DE MEDITAÇÃO NA UNIVERSIDADE COMO UMA ALTERNATIVA PARA REDUZIR A ANSIEDADE E $O$ ESTRESSE
}

DOI: 10.37702/2175-957X.COBENGE.2021.3742

Erika Mendonça Britto Passos - erikapassos@maua.br

Instituto Maua Tecnologia

Rua Alfredo Rullo Rizotti 38

04343-070 - SÃO PAULO - SP

Cristiane Maria Barra da Matta - cristianebarra@maua.br

Instituto Mauá de Tecnologia

R. Francisco Cruz 462

04117-091 - São Paulo - SP

Resumo: $O$ yoga tem um conjunto de valores e princípios que fazem com que seja um excelente conteúdo para ser apresentado e incluso no ambiente acadêmico. Seguindo esta linha de pensamento, esta pesquisa tem por objetivo refletir as influências do yoga em relação ao comportamento dos alunos perante situações de estresse e ansiedade. Os estudantes escolheram a atividade de Yoga e Meditação para complementar a carga horária de uma disciplina de Projetos e Atividades Especiais, oferecida pela universidade. A prática aconteceu uma vez por semana por um período de três meses e, ao término, foi solicitado um relatório para que os alunos apontassem as percepções sobre a yoga, com algumas questões propostas para auxiliar o relato. Observou-se que a prática do yoga e da meditação trouxe influências positivas aos praticantes, auxiliando na percepção de menores níveis de ansiedade e estresse, assim como numa sensação de paz, equilíbrio, relaxamento e bem-estar. Espera-se que esta pesquisa possa auxiliar futuros estudos sobre a prática do yoga nas universidades.

Palavras-chave: Yoga. Ansiedade. Bem-estar. Melhor Rendimento. 


\section{A PRÁTICA DE YOGA E DE MEDITAÇÃO NA UNIVERSIDADE COMO UMA ALTERNATIVA PARA REDUZIR A ANSIEDADE E O ESTRESSE}

\section{INTRODUÇÃO}

Alguns estudos vêm considerando que parte do estresse da população jovem universitária pode ser proveniente do esforço associado a metas futuras e à escassez de tempo para dedicar à vida pessoal. Considera-se que, durante o curso, há uma demasiada preocupação relacionada à entrada no mercado de trabalho ou ao ingresso em programas de estágio, o que implica dedicação, sacrifício e resistência física e emocional dos alunos, resultando em pouco tempo para outras atividades.

No presente trabalho relata-se a experiência dos estudantes de Engenharia na prática de Yoga e de Meditação semanal com a proposta de melhora no rendimento acadêmico e redução da ansiedade e do estresse.

A prática de Yoga e Meditação foi oferecida por um semestre como atividade da disciplina Projetos e Atividades Especiais, onde os estudantes escolheram cursos que somavam 160h por ano. Os Projetos e Atividades Especiais (PAEs) são um componente curricular oferecido pela instituição e são obrigatórios para cumprir a carga horária prevista pelo projeto pedagógico. $O$ curso relatado no presente trabalho tem tema " $A$ prática de Yoga e Meditação para controle da ansiedade no período das avaliações".

A prática de Yoga e Meditação, como forma de compor a carga horária do curso, foi introduzida na universidade pesquisada em 2017 com a participação de elevado número de estudantes, realizada inicialmente no ginásio de esportes. Após um ano, uma sala foi adaptada e preparada para a prática, o que melhorou muito a dedicação à yoga e a concentração nas meditações.

$\mathrm{Na}$ situação de pandemia COVID-19 a Atividade foi oferecida com o uso de tecnologia, com transmissão de aula síncrona.

Nessa publicação foram apresentadas as percepções dos estudantes, apontadas nos relatórios entregues ao final do semestre, após três meses de curso.

\section{REFERENCIAL TEÓRICO}

O Yoga é um complexo sistema de práticas espirituais, morais (disciplina) e físicas que visam atingir a "autoconsciência" ou "autorrealização". Hatha Yoga, o sistema no qual grande parte do yoga ocidental é baseado, é composto de diferentes elementos, tais como posturas (asanas), exercícios de respiração (pranayama), relaxamento (yoganidra) e meditação (dharana). E, apesar de o yoga não ser uma terapia, tem sido cada vez mais utilizado com sucesso no tratamento de estresse e ansiedade (Kirkwood, Rampes, Tuffrey, Richardson \& Pilkington, 2005). Além de ser uma intervenção não farmacológica, as terapias baseadas no yoga não têm efeitos adversos (ou mínimos) e podem ser praticadas pelo indivíduo após recomendações específicas (Ramaratnam \& Sridharan, 2005).

Esta tendência também se espalhou internacionalmente, com o surgimento de centros de yogaterapia, inclusão da prática de yoga e meditação em programas de câncer em hospitais, centros de medicina alternativa afiliados e o estabelecimento de uma nova geração de clínicos chamados yogaterapeutas. Pesquisas sobre os efeitos psicofisiológicos do yoga começaram em $1920 \mathrm{com}$ o trabalho de Kuvalayananada (Khalsa, 2004), mas as pesquisas sobre as aplicações terapêuticas do yoga, e meditação, começaram após a 
década de 70 (Gharote, 1977). Ainda assim, infelizmente, a quantidade de estudos presentes na literatura é insuficiente, impedindo que os pesquisadores cheguem a conclusões definitivas.

Oken e colaboradores (2006) investigaram, em 135 idosos saudáveis, os benefícios do yoga no humor e na função cognitiva. Os participantes do grupo de yoga experimentaram as práticas como um evento positivo que trouxe consequências benéficas para suas vidas. Os autores concluíram que indivíduos podem melhorar o bem-estar, assim como reduzir a ansiedade e as taxas de depressão através da aprendizagem e aplicação de um programa baseado no yoga.

Outra investigação (Malathi \& Damodaran, 1999) observou o papel do yoga na redução dos níveis de ansiedade em períodos que precediam provas e exames importantes, em um grupo de estudantes de medicina.

Uma das contribuições mais importantes do yoga para a educação é trazer a atenção para o agora, pois em um contexto em que há um uso quase compulsivo do celular, das redes sociais, da internet, manter a atenção dos alunos nas aulas se transforma em um desafio, porém quando um aluno executa uma posição de equilíbrio, se ele não estiver atento, cairá ao chão (Borges \& Micol, 2016). Logo, o yoga exige que o aluno esteja totalmente concentrado na aula para poder conseguir executar as asanas (posturas).

O yoga possui vários benefícios terapêuticos na promoção da saúde e da qualidade de vida do seu praticante (Battison,1998). Melhora o cognitivo, o equilíbrio emocional, reduz a excitabilidade ou apatia psicofísica, melhora a assertividade e afetividade, 0 autocontrole da ansiedade e reduz sintomas físicos e emocionais do estresse (Baptista, 2002). A literatura cita-se ainda que a prática de yoga reduz os sintomas de depressão, de dores crônicas e promove significativa melhora do sono e do bem-estar geral (Woodyard, 2011).

\section{MÉTODO}

As aulas de Yoga e Meditação possui a mesma duração das aulas regulares da grade curricular, $1 \mathrm{~h}$ e 40min. A programação dessas aulas está dividida em três etapas. Uma primeira etapa com duração de $30 \mathrm{~min}$ em que textos sobre a teoria de yoga são lidos, ou vídeos são assistidos, e posteriormente discutidos, para entender a filosofia do yoga. A segunda etapa com duração de 60 min refere-se à prática das posturas estruturadas baseada nos princípios do Hatha Yoga, finalizando com o relaxamento (10 min). A terceira e última etapa, dedica-se à Meditação para tranquilizar a mente e trabalhar a respiração.

Tudo é muito novo nessa dinâmica da aula de Yoga e Meditação. No primeiro contato busca-se saber o que fez o aluno escolher essa atividade. A maioria dos estudantes relataram estar à procura de uma alternativa para reduzir o estresse e a ansiedade. Alguns citaram que se inscreveram no curso por curiosidade e em busca de algo diferente das opções tradicionais da área acadêmica.

Após três meses de curso solicita-se aos alunos a entrega de um relatório que aponte as percepções sobre a prática da yoga. Nesse relatório algumas questões são propostas para auxiliar o relato dos alunos, como por exemplo, "Na sua opinião, a prática de Yoga pode ajudar na concentração durante estudo e realização das provas? Descreva sua experiencia.", "Após 3 meses de prática de Yoga e Meditação algo mudou no seu cotidiano? Comente ou justifique sua resposta". 


\section{(CCOBENCE de Educação em Engenharia 2021 \\ 28 a 30 de SETEMBRO \\ - Evento Online \\ "Formação em Engenharia: \\ Tecnologia, Inovação e Sustentabilidade"}

\section{RESULTADOS}

As Figuras 1, 2, 3 e 4 apresentam as práticas na sala adaptada para o curso de Yoga e Meditação.

Figura 1 - Alunos na prática de yoga.

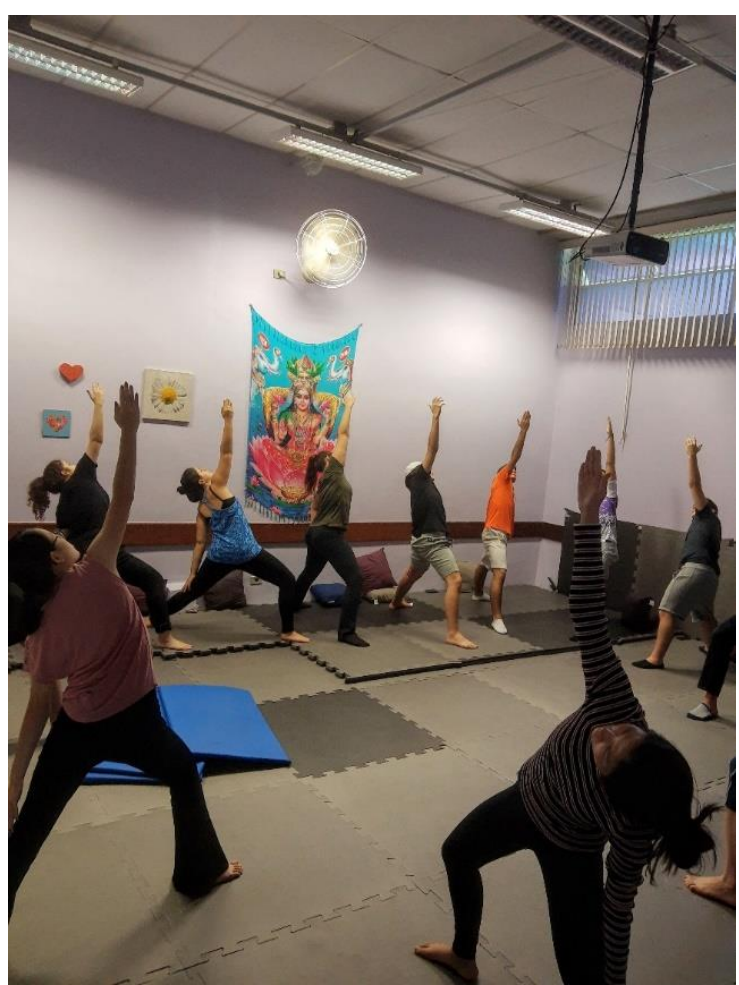

Fonte: a autora.

Figura 2 - Alunos no relaxamento.

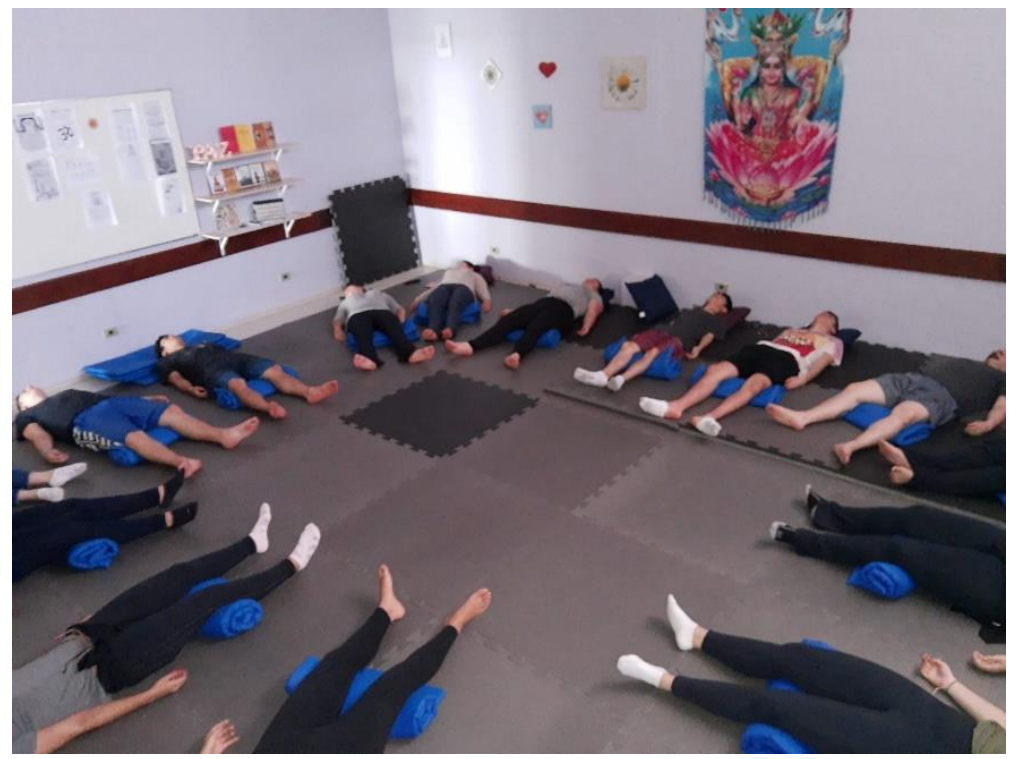

Fonte: a autora. 


\section{CCOBENCE 2021 a

Figura 3 - Alunos na meditação.

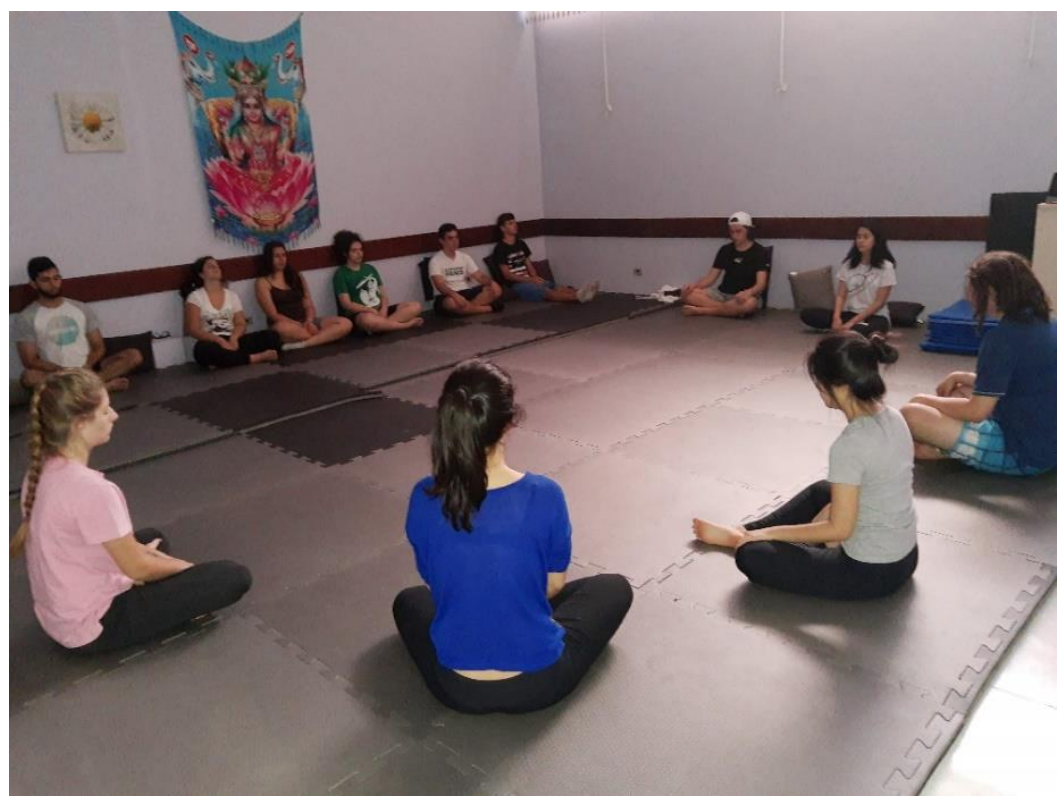

Fonte: a autora.

Figura 4 - Alunos na reflexão após leitura.

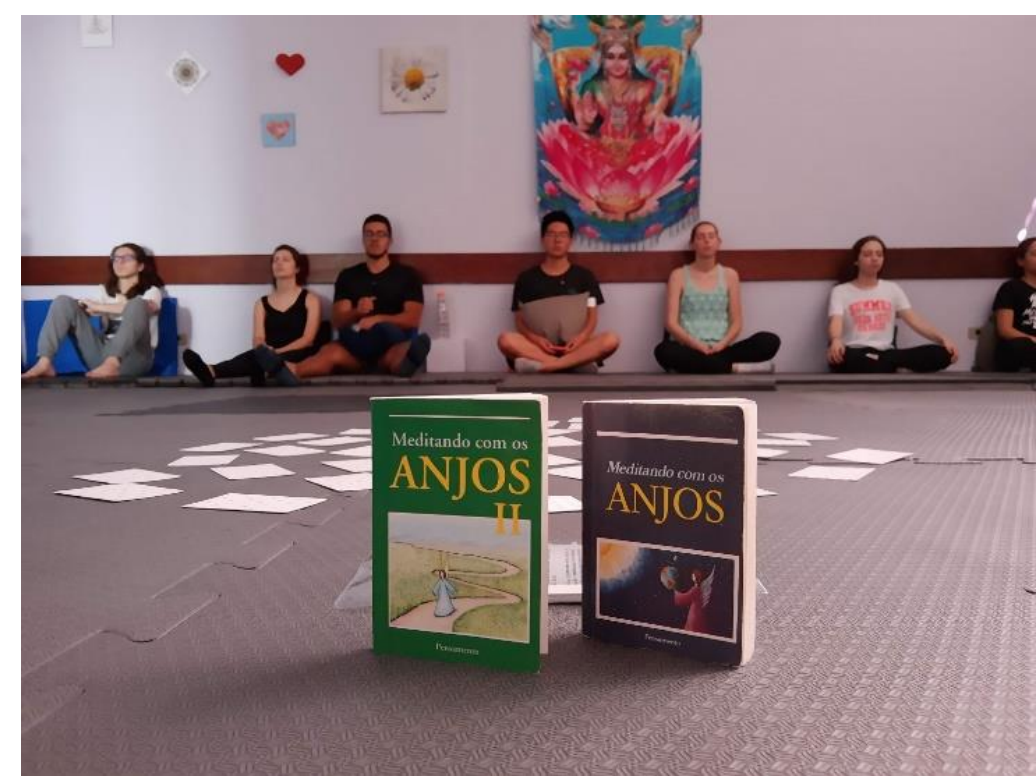

Fonte: a autora.

Nas Tabelas 1 e 2 são apresentados os relatos das experiências dos alunos, referente às questões do relatório. 
Tabela 1 - Respostas dos relatórios finais dos anos de 2018 e 2019, antes da pandemia COVID-19.

Na sua opinião, a prática de Yoga pode ajudar na concentração durante estudo e realização das provas? Descreva sua experiencia.

A prática da Yoga permite que possamos alcançar um equilíbrio e uma paz interior, isso é super relevante, pois por meio desse equilíbrio podemos obter um nível elevado de concentração e dessa forma atingir um bom resultado nos estudos e nas respectivas provas.

Sim, pois pode desprender as pessoas de alguns sentimentos, como nervosismo e ansiedade, que tem o potencial de atrapalhar significativamente as pessoas no estudo, concentração e até para dormir.

Nos dias que fazia Yoga na PAE, eu sentia muito mais qualidade no sono.

A Yoga com certeza é uma prática fundamental para concentração e foco, assim como, para a ansiedade e estresse.

A prática quase diária me proporcionou um equilíbrio mental e está me ajudando a ver o mundo com outra perspectiva. Fez com que eu aprendesse a respirar minutos antes da prova para acalmar.

Acredito que sim, pois uma pausa nos estudos é necessária para que possamos aprender melhor o que estamos estudando. E é ainda melhor se essa pausa nos ajude a relaxar sem a interferência de celulares ou outros problemas que possamos estar passando naquele momento.

Sim, durante meus estudos procuro pausar e meditar por 5 minutos, para relaxar e conseguir focar mais. Logo, isso também me ajuda ir bem nas provas, pois consigo focar mais e entender os conteúdos.

Eu realmente compreendi o qual é essencial termos um cuidado conosco. Muitas das vezes no ano passado, havia reparado como a Professora Erika era tão calma, e não entendia o porquê. Hoje vejo que o é praticado por ela, é inserido em seu dia a dia. Seu hábito à torna uma pessoa muito tranquila, que transmite paz ao falar.

A PAE de Yoga, primeiramente, não parece ser de grande importância para muitas pessoas, porém o comparecimento a ela pode mudar totalmente a opinião de qualquer um.

O estresse e falta de concentração na vida de qualquer estudante, e eu como uma posso dizer, é muito comum, e traz consigo muitos prejuízos. E uma solução para grande parte desses problemas seria a Yoga, o que funcionou para mim.

siiiiiiiiiiiim, porque durante as aulas a professora pede muito pra se concentrar na respiração, isso acaba meio que fazendo com que você preste mais atenção e isso acaba acalmando, e não só para os estudos e provas como pra vida também. Porque logo depois na aula eu me sinto leve por mais que alguns exercícios sejam um pouco doloridos, mais ajuda muito a mente e o corpo.

Acredito que a PAE de Yoga e Meditação foi muito benéfica, já que existia na semana um espaço de tempo reservado exclusivamente ao meu bem-estar. Hoje em dia, com a vida corrida que todos têm, é muito raro ter oportunidade de ter esses momentos sem preocupação do que virá depois, do que fiz certo ou errado, o que falta fazer, etc. Assim, acredito que agregou muito, porque depois da aula estava sempre mais disposta para realizar todas as outras tarefas do dia e da semana. Foi um aprendizado para a vida: posso realizar a prática sozinha e melhorar a cada vez que treinar.

Sim. Antes de conhecer a aula e saber sobre o que é a yoga, não conseguia me concentrar direito nos estudos, ficava muito ansioso, agitado e acabava me atrapalhando. Hoje consigo pensar muito mais antes de fazer, respiro é assim tomo uma decisão.

Fonte: Resultado dos questionários.

Tabela 2 - Respostas do relatório final do ano 2020, durante a pandemia COVID-19. 
Após esses 03 meses de prática de Yoga e Meditação algo mudou no seu cotidiano? Comente e ou justifique sua resposta.

Me tornei uma pessoa mais calma e senti uma melhora no meu equilíbrio e nas emoções. Quando me sinto muito ansiosa/agitada tento controlar minha respiração em 4 tempos como foi praticado durante as aulas e quando tenho tempo livre tento praticar Yoga em casa.

A prática do Yoga me fez relaxar diante das tensões do dia a dia, me levou para um estado que nunca imaginei que fosse possível, me ajudou a me acalmar diante de situações complicadas e me interessar pela meditação.

Comecei a reservar alguns minutos de quase todos os dias para meditar e me conectar com o meu próprio ser. Acredito que as aulas em conjunto com a meditação em casa foram essenciais para o aumento da concentração e da tranquilidade no cotidiano.

A PAE de Yoga me proporcionou momentos de tranquilidade muito bons, mas a principal coisa que levarei comigo e que irei continuar a aplicar em meu dia a dia é a técnica de respiração para relaxamento, pois percebi que isso me ajudou nos momentos de estudo e provas.

Sim, mesmo que não seja tão perceptível, em situações de ansiedade/crises aumentou a facilidade de controlar a respiração e consequentemente se acalmar, além da melhora na postura.

Para mim, a yoga ajudou com o estresse e ansiedade. Antes, em certos momentos, eles me faziam mal de modo que eu sentia que tinha perdido controle do meu corpo. Agora eu sinto que tenho esse controle de volta o que me deixa mais calma, além de eu ter consciência de que preciso respeitar meus limites e não ficar me sobrecarregando. A yoga também me ajuda a relaxar os músculos, o que melhora as dores causadas pela má postura e tensão do dia.

Sim, tive uma grande melhora em dores que possuía nas costas, me senti mais tranquilo e relaxado quanto a problemas que surgiam na minha vida e conseguia manter minha cabeça mais calma para lidar com eles de uma forma melhor do que lidaria antes, tive muito menos discussões e por fim tive uma aproximação familiar melhor com minha mãe por toda essa calma e responsabilidade que acabei criando.

Sim, pois o Yoga exercita sua mente enquanto a meditação exercita e relaxa o cérebro. Os estudos depois da aula de Yoga sempre foram mais produtivos.

Sim. Nossos sentimentos influenciam muito nosso rendimento na prova, quando estamos nervosos nossa respiração fica muito desregulada, assim, sabendo controlar a respiração fica mais fácil de manter o foco e não se desesperar.

Sim, a sua prática me levou a clarear a mente, principalmente esse ano em que eu tive muitas complicações pessoais, sendo assim, consigo me focar muito mais e fazer as coisas uma de cada vez, sem sofrer com a ansiedade.

Sim, pois a Yoga ajuda a treinar a concentração tanto nas posturas como na meditação, "esvaziando a mente", o que ajuda a focar em uma só coisa, como nos estudos.

Sim, toda segunda feira depois do Yoga eu me sentia mais leve e conseguia prestar mais atenção nas aulas que eu tinha depois e consegui melhorar minhas notas.

Com certeza. Percebi que me sinto menos ansiosa com a prática, e isso influi diretamente na forma como estudo. Consegui, com o foco mais apurado pela tranquilidade que a prática possibilita, perceber meus pontos fracos, sem pensar neles como fracassos, mas sim, como pontos para melhoria, de forma mais tranquila.

Com certeza, depois de começar a prática, quando estou em uma situação onde fico nervoso ou ansioso, eu focalizo na respiração e no estado que meu corpo fica quando medito, com isso consigo ficar muito mais calmo.

Fonte: Resultado dos questionários. 
A partir dos relatos, verificou-se que a maioria dos alunos perceberam os benefícios da Yoga e da Meditação, assim como do embasamento teórico para compreender a proposta. Essa percepção positiva da yoga pelos jovens universitários, inicialmente à procura de algo para estabilização emocional e comportamental, após três meses de prática de uma vez por semana mostrou rápida resposta.

Os maiores benefícios apontados, nesse estudo, pela prática foram a sensação de paz e calma, relaxamento e melhora na qualidade do sono, redução da ansiedade e do estresse, melhora na concentração (foco) e nos estudos, equilíbrio emocional e bem-estar. Esses resultados corroboram com os autores Kirkwood, Rampes, Tuffrey, Richardson \& Pilkington (2005), Malathi \& Damodaran (1999), Borges \& Micol (2016), Baptista (2002) e Woodyard (2011).

O yoga ajuda a diminuir a ansiedade por causa do efeito no sistema nervoso. A prática de asanas (posturas), respiração, relaxamento e meditação abaixam os níveis de hormônios responsáveis pela aceleração do organismo. O yoga também equilibra os batimentos cardíacos e acalma a respiração, problemas comuns em pessoas que sofrem de ansiedade. Além disso, pesquisas têm comprovado cientificamente que a prática de yoga pode ajudar no funcionamento cerebral. Estudos comprovaram que uma sessão de uma hora estimula os níveis do neurotransmissor ácido gama-aminobutírico (GABA) no cérebro. Níveis baixos de GABA estão associados à ansiedade e depressão (Biasetti, 2012).

Um estudo realizado por Bahtt (2011), revelou a redução significativa em emoções negativas, tais como a tensão e ansiedade, raiva e hostilidade, fadiga e inércia depois de algumas aulas de yoga. A observação pode ser explicada pela técnica de respiração utilizada, que cria um estado de ativação do sistema nervoso simpático, responsável por reduzir essas emoções. Outros resultados encontrados foram relacionados com o estado de alerta que envolve o foco e a atenção na respiração, ou em músculos específicos de determinadas partes do corpo, que indica que o yoga melhora as capacidades de atenção, que por sua vez leva a um maior relaxamento.

Revisões sistemáticas indicam que o yoga pode ser considerado uma opção de tratamento auxiliar viável e seguro para pacientes com doenças cardiovasculares, diabetes do tipo 2, doença obstrutiva pulmonar crônica, transtorno de estresse pós-traumático e com níveis elevados de depressão. Assim, diante desse cenário de pandemia e isolamento social, a prática regular de yoga parece ser uma terapia bastante promissora no controle dos níveis de estresse, ansiedade e depressão (Souza, 2017).

A proposta apresentada nesse estudo, na prática de yoga não somente como atividade física, mas como compreensão sobre uma filosofia de vida, propõe uma reflexão sobre o autoconhecimento. Acredita-se no êxito dessa proposta e na possibilidade de futuras pesquisas envolvendo instrumentos validados de ansiedade, estresse e depressão, assim como relações entre Yoga, espiritualidade, autoeficácia e adaptação acadêmica.

\section{CONCLUSÕES}

Compreendeu-se que os estudantes universitários enfrentam muitos desafios acadêmicos, de aprendizagem, de socialização, desenvolvimentais, pessoais e emocionais, ainda reforçados pela pandemia do COVID-19, e que a prática de yoga e de meditação podem auxiliar na percepção de menores níveis de ansiedade e estresse, assim como numa sensação de paz, equilíbrio, relaxamento e bem-estar. Os benefícios apontados, percebidos pelos estudantes desse estudo, mostraram como consequência melhor concentração nos estudos e melhor aproveitamento do curso. 


\section{REFERÊNCIAS}

BAHTT, J. Impact of Yoga on negative emotions and affects. Indian Journal of Applied Basic Medical Sciences, v.13, n.17, 2011.

BARDAGI, M. P.; HUTZ, Claudio Simon. Eventos estressores no contexto acadêmico: uma breve revisão da literatura brasileira. Interação em Psicologia, Curitiba, v. 15, n. 1, p. 111-119, 2011.

BATTISON, T. Vença o Stress. São Paulo: Manole, 1998.

BORGES, J. J. S.; MICOL L. Corpos comunicantes: rumos do yoga na educação.

Simpósio Internacional de Educação e Comunicação, 2016, Aracajú. Universidade Tiradentes, 2016.

CABO VERDE, Evandro Jorge; GARCIA, Mayra Nascimento; RODRIGUES, Gislayne Costa. A Influência do Yoga no ambiente Escolar. RHE- Revista Educação e Humanidades, UFAM, 2020.

GONÇALVES, Nilo Pedro da Cunha. Influência de um programa de yoga no desempenho da força, potência, flexibilidade e equilíbrio, nos níveis de stress na qualidade de vida escolares no ensino médio. Afluente: Revista de Letras e Linguística, v. 3, n.7, p. 9-20, Portugal, 2018.

SOUZA, Deise Coelho de. Condições emocionais de estudantes universitários: estresse, depressão, ansiedade, solidão e suporte social. Dissertação de Mestrado apresentada ao Programa de Pós-Graduação em Psicologia da Universidade Federal do Triângulo Mineiro, como requisito parcial para obtenção do título de Mestre em Psicologia. Uberaba, MG, 2017.

TENORIO, Joana Inês Ferreira. A influência da prática de yoga no bem-estar afetivo e na satisfação com a vida. Mestrado integrado em psicologia, Universidade de Lisboa, 2014.

VORKAPIC, Camila Ferreira; RANGE, Bernard. Os benefícios do yoga nos transtornos de ansiedade. Rev. bras. Ter. cogn., Rio de Janeiro, v. 7, n. 1, p. 50-54, 2011.

\section{YOGA AND MEDITATION PRACTICE AT THE UNIVERSITY AS AN ALTERNATIVE TO REDUCE ANXIETY AND STRESS}

Abstract: Yoga has a set of values and principles that make it an excellent content to be presented and included in the academic environment. Therefore, this research aims to reflect the yoga influences in relation to students' behavior with stress and anxiety. The students chose the Yoga and Meditation activity to complement the workload of a discipline of Projects and Special Activities, offered by the university. The practice happened once a week for a period of three months and, at the end, a report was requested for the students to point out the perceptions about yoga, with some questions proposed to assist the report. 
It was observed that the practice of yoga and meditation brought positive influences to the practitioners, helping in the perception of lower levels of anxiety and stress, as well as in a feeling of peace, balance, relaxation and well-being. It is hoped that this research will help future studies on the practice of yoga in universities.

Keywords: yoga, anxiety, welfare, academic performance. 